\title{
Damage evolution in GLARE fibre-metal laminate under repeated low-velocity impact tests
}

Research Article

\author{
Freddy D. Morinière ${ }^{1 *}$, René C. Alderliesten ${ }^{1}$, Mehdi Yarmohammad Tooski ${ }^{2}$, Rinze Benedictus ${ }^{1}$ \\ 1 Structural Integrity \& Composites Group, Faculty of Aerospace Engineering, Delft University of Technology, \\ Kluyverweg 1, 2629HS Delft, The Netherlands \\ 2 Faculty of Mechanical Engineering, K.N. Toosi University of Technology, Pardis St., Molasadra Ave., Vanak SQ., Tehran, Iran
}

Received 30 March 2012; accepted 18 June 2012

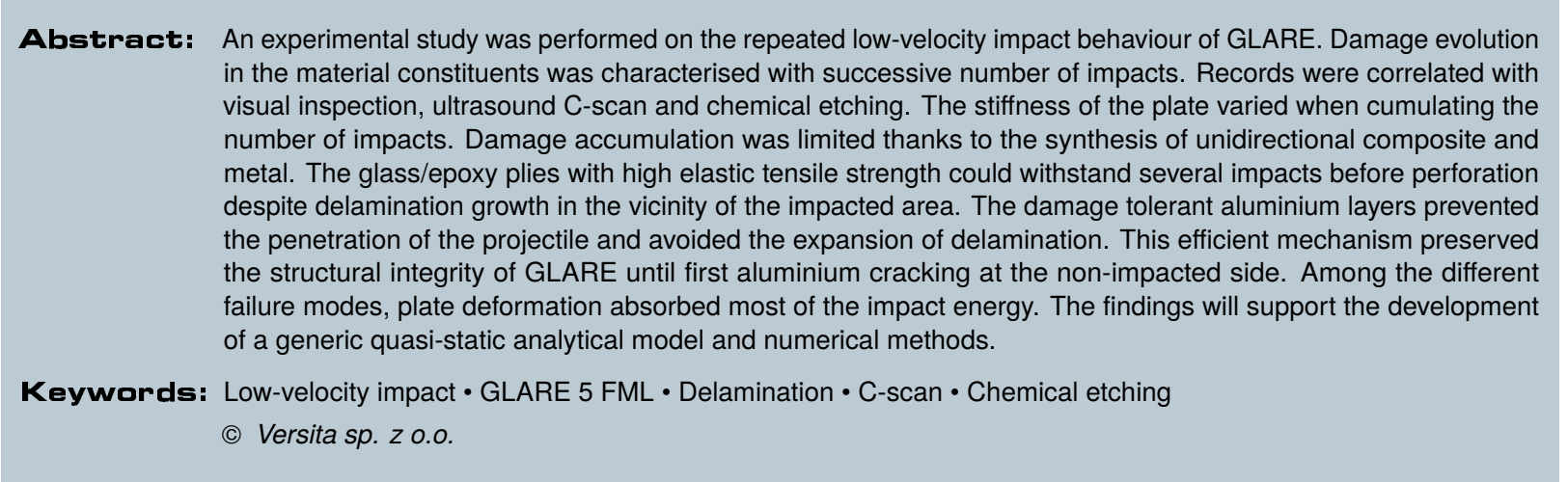

\section{Introduction}

GLARE Fibre-Metal Laminate (FML) consists of alternating S2-glass/FM94-epoxy composite plies and 2024T3 aluminium layers. GLARE FMLs are lightweight hybrid composites that offer better damage tolerance characteristics than plain composite and monolithic aluminium. Thanks to their excellent damage tolerance capabilities they have gained interest from the aerospace industry $[1,2]$.

*E-mail: F.D.Moriniere@tudelft.nl
Several studies have evaluated the impact performance of FMLs upon minimum cracking energy and perforation energy at low-velocity impact [3-5]. However, damage size cannot be characterised only by the level of absorbed energy [6-8]. Caprino [9], Laliberté [10] and Liu [7] performed single impact tests at different energy levels until the penetration limit in order to reconstruct damage creation and damage growth stages in FMLs. The impact damage resistance of different materials can be compared with this method. To evaluate the impact damage tolerance, a technique consists in performing repeated impacts at the same low level of impact energy. Damage evolution is assessed stepwise and failure mechanisms are highlighted. This practice is extensively used for composites $[8,11,12]$. Only Rajkumar [13-15] applied it to woven FMLs man- 
ufactured at low pressure. Yet, the observations are not representative of the standard GLARE grades made of unidirectional fibres and cured at high pressure. Besides, each of the described failure modes could not be identified with the available data.

In this paper a thorough characterisation of the impact damage tolerance of GLARE 5-2/1-0.3 will be presented. This experimental survey will determine the failure modes and the sequence at which they occur to give a general understanding on the impact behaviour of FMLs.

\section{Test method}

GLARE 5-2/1-0.3 laminates were manufactured using a hand lay-up technique. These plates consisted of a composite core of $\left[0^{\circ} / 90^{\circ} / 90^{\circ} / 0^{\circ}\right] \mathrm{S} 2-$ glass/FM94-epoxy composite prepreg embedded in two layers of $0.3 \mathrm{~mm}$-thick 2024 T3 aluminium alloy. The specimens were cured during 3 hours in an autoclave cycle with high pressure, i.e. 6 bar maximum, and a cure temperature of $120^{\circ} \mathrm{C}$. With a metal volume fraction of $54 \%$ and a nominal thickness of $1.1 \mathrm{~mm}$, these laminates weighed $2.64 \mathrm{~kg} / \mathrm{m}^{2}$.

Repeated impacts were performed on rectangular plates of $150 \mathrm{~mm}$ by $100 \mathrm{~mm}$ placed between two square frames of $160 \mathrm{~mm}$ by $160 \mathrm{~mm}$ with a $125 \mathrm{~mm}$ by $75 \mathrm{~mm}$ opening, as shown in Figure 1(a). The plates were fully clamped by 6 bolts with a torque of $40 \mathrm{~N} \cdot \mathrm{m}$. The specimens were oriented so that the rolling direction and the $0^{\circ}$ fibre direction were along the major axis of the rectangular opening. A conical-shaped steel impactor of $124 \mathrm{~g}$ was defined by a hemispherical nose $6.35 \mathrm{~mm}$ in radius, see Figure 1(b). A total mass of $1 \mathrm{~kg}$ hit the samples at the centre with an energy level of $6.6 \mathrm{~J}(3.6 \mathrm{~m} / \mathrm{s})$ until penetration. The experimental arrangement is depicted in Figure 2. Using this in-house instrumented drop-weight test set-up, the velocity of the impactor nose prior to impact was measured as it interrupted the two laser beams separated from a known distance. The contact force $F(t)$ between impactor and specimen was measured by a load cell located in the impactor nose. This force signal was integrated numerically to obtain the velocity $v(t)$, displacement $d(t)$ and absorbed energy $E(t)$. Based on the Fasanella data filtering technique [16], the complete measuring and processing program is described in [17].

The first specimen was impacted once, the second, twice and so forth. Penetration was defined as the projectile passed through the thickness of the target. After each impact the impactor was caught to prevent rebound. Damage characteristics were described by visual inspection, data analysis, and by both destructive and non-destructive techniques to assess impact damage in the laminates. The impacted specimens were first C-scanned and then chemi-

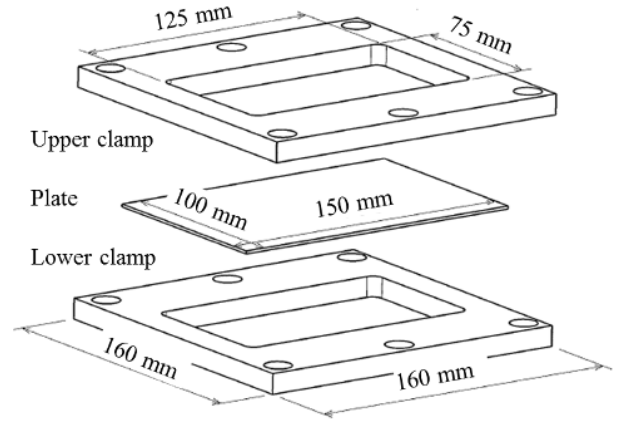

(a)

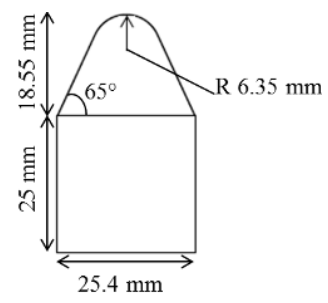

(b)

Figure 1. a) Test fixture and b) profile of the impactor nose.
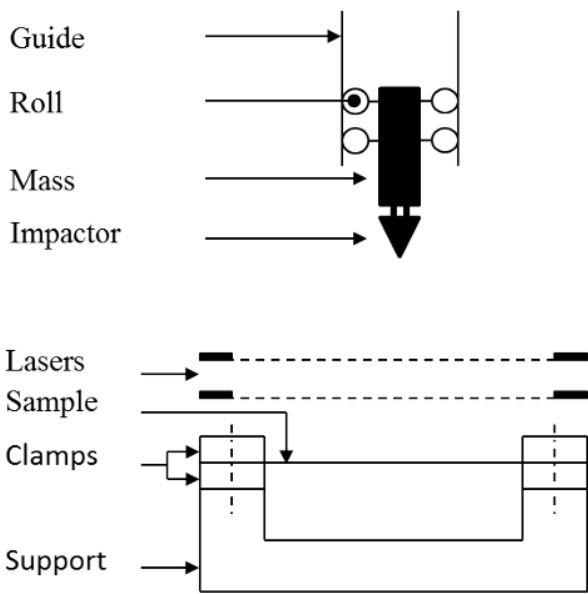

Figure 2. Schematic of the drop test set-up.

cally etched. The C-scan imaging was conducted using a Midas-NDT system with a $10 \mathrm{MHz}$ narrow beam ultrasonic transducer in single through-transmission mode.

\section{Results}

\subsection{Damage characterisation}

Figure 3 describes the damage evolution in GLARE 5-2/10.3 under repeated low-velocity impacts until the penetration threshold. The front, lateral and back sides are 
Rolling direction $/ 0^{\circ}$ fibre direction / major axis of the rectangular plate

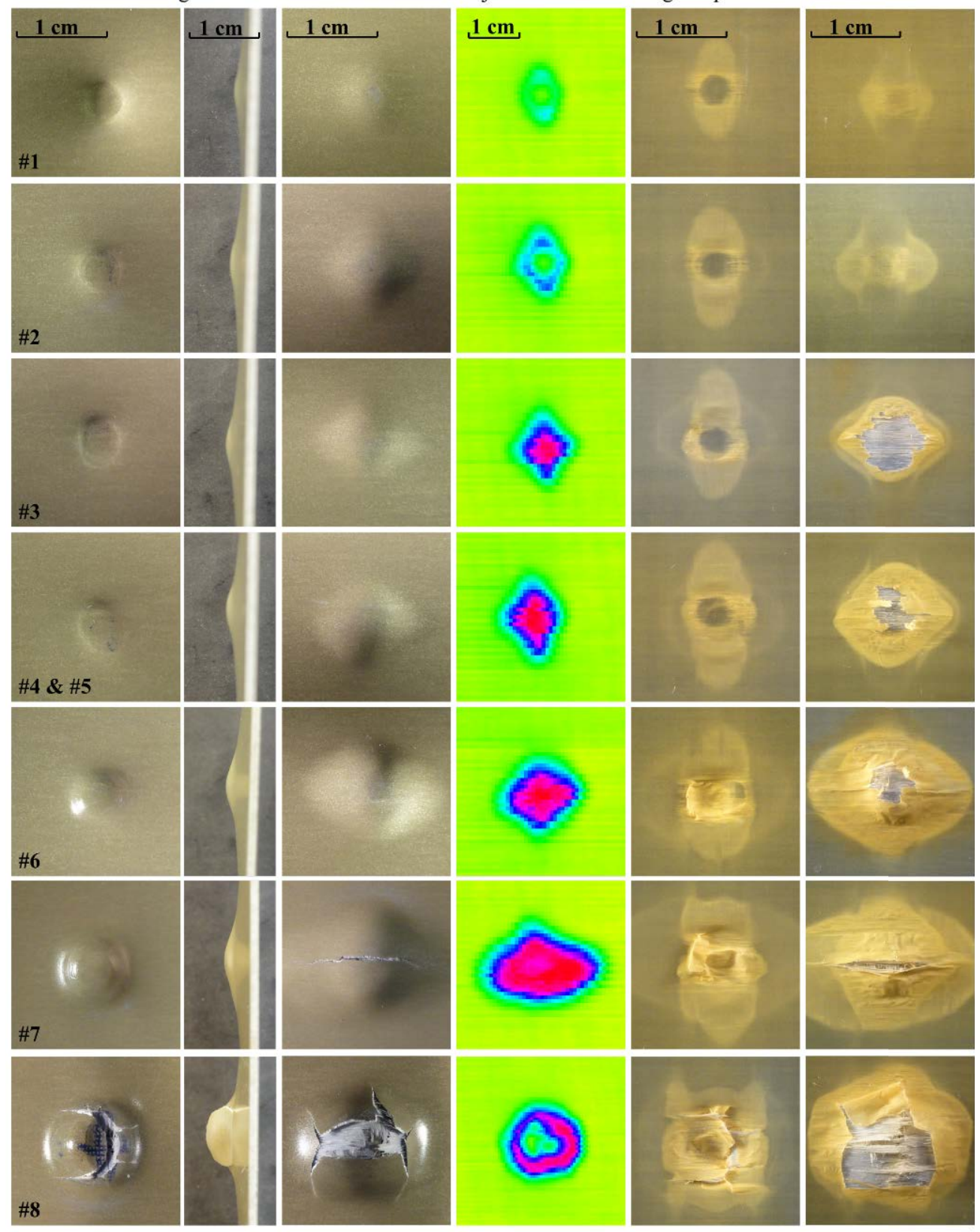

Figure 3. Views of front, lateral and back sides, C-scan, etched front and back sides of GLARE 5-2/1-0.3.

presented with the corresponding $\mathrm{C}$-scanned and etched views. As obvious from these pictures, the entire damage contour increased with higher cumulative number of impacts. The following description states when the different types of damage initiated.

$1^{\text {st }}$ impact: Damage occurred. A lateral permanent deformation amounted to 3 times the plate thickness. By inspecting the etched views, matrix cracking was detected thanks to white stripes along the $0^{\circ}$ fibre direction that were visible on both sides. Despite internal damage in the composite plies, both top and bottom interfaces with the metal layers were intact. Concurrently, delamination (dark green zone in C-scan view) initiated between the composite plies at the periphery of the impact location at the top side and developed along the minor axis of the plate. Nevertheless, it started under the impacted zone at the bottom side along the major axis. In the impacted aluminium layer a visible dent was delimited by a circular 
hinge line which defined the contact area. In the nonimpacted aluminium layer a prominent peak remained at the centre of the impacted zone.

$2^{\text {nd }}$ impact: Delamination slightly expanded in the same directions as described earlier. Matrix cracking was more pronounced as seen in the etched views. Though it initiated previously, it was detected from that moment in the blue region of the $\mathrm{C}$-scan view. No variation was found with respect to the aluminium layers. The lateral plastic deformation rose to 3.5 times the plate thickness.

$3^{\text {rd }}$ impact: A few fibres started to fracture (etched sides and red area in $\mathrm{C}$-scan image). At the impacted side fibres broke around the impact location while it happened in the middle of the impact location at the non-impacted side. Delamination kept growing. Disbonding took place in the bondline between aluminium and composites (dark blue region in C-scan picture and the adhesive could be peeled off as seen in the etched back view). The impacted aluminium side disbonded to composites at the periphery of the contact area whereas at the non-impacted side it happened in the whole delamination zone. No change in damage type was found for the aluminium layers. The lateral deformation marginally increased.

$4^{\text {th }}$ and $5^{\text {th }}$ impacts: The plate permanently deflected to 4 times the plate thickness. The damage modes enlarged as described before. The front aluminium layer had still a visible dent and the back one, a prominent peak.

$6^{\text {th }}$ impact: Unlike impact \#5, a crack in the distal aluminium initiated from the centre of the impacted zone along the rolling direction while the top aluminium layer remained intact with a visible dent. Disbonding at the impacted side reached finally the centre of the impacted zone. Since then, both aluminium layers were completely disbonded at the impact location as pictured in the etched views. Two clear lines of fibre fracture along the rolling direction were observed at the periphery of the contact area at the impacted side whereas fracture was in the middle of the impacted zone at the non-impacted side. The other aforementioned failure modes enlarged and the permanent flexure reached 4.2 times the plate thickness.

$7^{\text {th }}$ impact: The distal crack in aluminium elongated. Still, the top aluminium did not crack though it contained a deeper dent. Delamination expanded mainly in the longitudinal direction at the back side while it progressed in the transverse direction at the front side. The permanent deflection amounted to 4.3 times the plate thickness.

$8^{\text {th }}$ impact: Penetration occurred. Fibre layers were totally fractured. At the non-impacted side the initial longitudinal crack in aluminium propagated until multiple cracks in the transverse direction initiated. Eventually, cracking in aluminium appeared at the impacted side around the contact area and secondary cracks developed perpendicular to the main crack. Aluminium layers underwent petaling

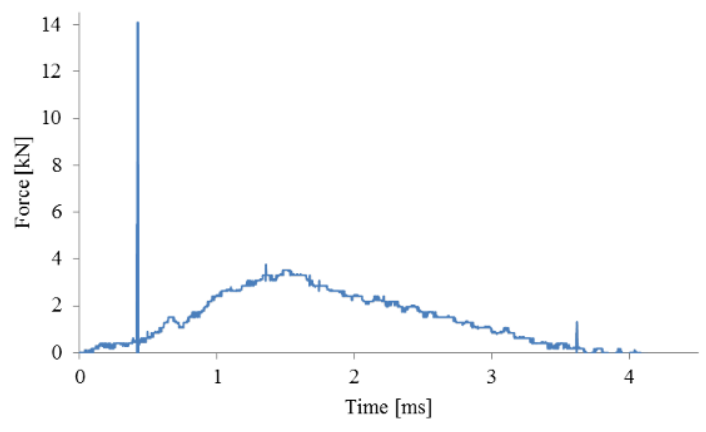

Figure 4. Recorded force-time curve at impact \#7 with damage initiation stages.

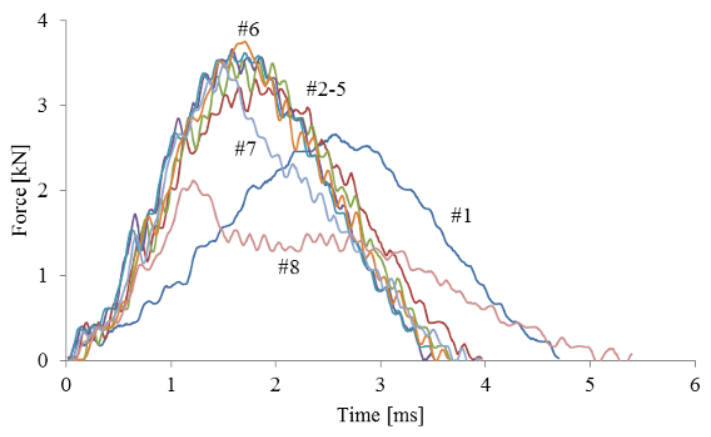

Figure 5. Mean force-time records.

[18]. The lateral plastic deformation reached 6.6 times the plate thickness.

\subsection{Damage detection}

Test records indicated also damage initiation. It could be tracked from the force-time curves as shown in Figure 4. The magnitude of the kink loads varied between $1 \mathrm{kN}$ and $14 \mathrm{kN}$. Given that about 4000 points were recorded in each test, a simple moving average on 100 points was used in the force-time data series to reduce data scatter and report longer-term fluctuations. Beforehand, the kinks highlighted in Figure 4 were deleted. From the modified curves in Figure 5 all the plots present ripples except \#1 that is less affected.

Figure 6 plots the absorbed energy versus the recorded displacement at each number of impacts. In order to better assess any differences, the permanent displacement from the previous test was added to offset the graphs starting from impact \#2. Two distinct aspects can be reported. A kink in the curve \#7 happened at $0.39 \mathrm{~J}$ and in \#8 at $0.28 \mathrm{~J}$. The slope in \#8 leans towards larger displacement. 


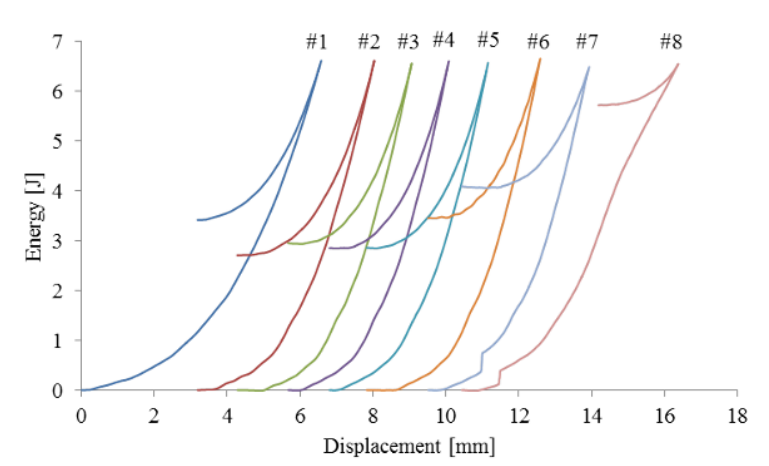

Figure 6. Energy-displacement curves with displacement off-set from impact \#2.

\section{Discussion}

\subsection{Influence of damage modes in the impact response}

Data acquired during the impact experiments give an interesting insight into the behaviour of GLARE under repeated impact loading.

Figure 7 illustrates the energy absorption ability of the impacted plates. The exact values of the absorbed energy at each impact are presented in Table 1. Successive impacts increased damage size, resulting in higher absorbed energy. Curves \#6-8 verify this trend. In these samples, metal layers were cracking and undergoing petaling which led to immediate penetration of the plate. However, at impacts \#2-5 the absorbed energy remained steady even if the delamination area was enlarging and fibres were breaking as seen in Figure 3. Thus, both delamination and fibre failure are quite low-energy absorbing failure modes. Despite the similarity in material thickness between composite and metal in GLARE 5-2/1-0.3, i.e. the metal volume fraction amounts to $54 \%$, aluminium failure modes absorb a significant quantity of energy whereas the glass/epoxy ones appear to be negligible.

Furthermore, the absorbed energy between impact \#1 and impact \#2 decreased by $21 \%$. Such a difference cannot be attributed only to aluminium yielding. Another mechanism comes into play: plate deformation. Maximum displacement at impact \#2 is $26 \%$ less than at impact \#1. Flexural displacement contributes greatly to absorbing impact energy.

It is known that the higher the stiffness, the sooner the peak energy becomes [6]. The stiffness variation between the curves \#1 and \#8, and \#2-7 needs further explanations. Stiffness variation in the impact response will be discussed in Subsection 4.4 .

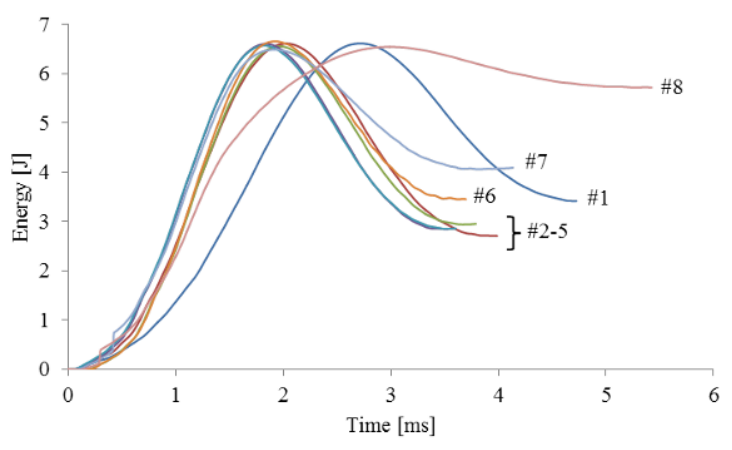

Figure 7. Energy-time records of repeatedly impacted panels.

Table 1. Level of absorbed energy of the repeated impact tests.

\begin{tabular}{lcc}
\hline & $\begin{array}{c}\text { Impact energy } \\
{[\mathrm{J}]}\end{array}$ & $\begin{array}{c}\text { Absorbed energy } \\
{[\mathrm{J}]}\end{array}$ \\
\hline \hline Impact \#1 & 6.62 & 3.42 \\
Impact \#2 & 6.62 & 2.71 \\
Impact \#3 & 6.56 & 2.95 \\
Impact \#4 & 6.61 & 2.85 \\
Impact \#5 & 6.57 & 2.86 \\
Impact \#6 & 6.66 & 3.47 \\
Impact \#7 & 6.49 & 4.09 \\
Impact \#8 & 6.55 & 5.72 \\
\hline
\end{tabular}

As seen in Figure 6 and Table 1, the flexural displacement becomes larger with the energy absorbed by the plate. This remark refers to the formula of strain energy in which strain energy is directly proportional to strain [19].

The kinks presented in Figure 6 show evidence of discontinuities in the plate response when penetration occurs. Relating these features to the observed phenomena, the kink at $0.39 \mathrm{~J}$ in the curve \#7 is probably due to the growth of the crack that initiated in the non-impacted aluminium layer. The one at $0.28 \mathrm{~J}$ in the curve \#8 is possibly the result of the crack initiation in the impacted aluminium layer. The flexural gain in the curve \#8 that emanates from petaling of aluminium certainly helps in absorbing a larger quantity of impact energy. This behaviour demonstrates that the plate is being penetrated.

The observations quoted before could be made likewise with the velocity-time curves as illustrated in Figure 8. In the kinetic energy formula, the energy is a function of the velocity.

The kinks observed in the force-time curves are reported in Table 2 in correlation with the observed damage. The difference in magnitude between the kink loads and the main curve suggests what type of damage initiated. High kinks are seemingly related to aluminium cracking whereas small kinks describe fibre failure. 
Table 2. Observed kink loads and estimated damage types.

\begin{tabular}{|c|c|c|c|c|c|}
\hline & $\begin{array}{l}\text { Contact duration } \\
{[\mathrm{ms}]}\end{array}$ & $\begin{array}{l}\text { Time at kink load } \\
{[\mathrm{ms}]}\end{array}$ & $\begin{array}{l}\text { Kink load } \\
{[\mathrm{kN}]}\end{array}$ & $\begin{array}{l}\text { Main load } \\
{[\mathrm{kN}]}\end{array}$ & $\begin{array}{c}\text { Estimated type of damage } \\
{[-]}\end{array}$ \\
\hline Impact \#5 & 3.60 & 0.69 & 2.63 & 1.50 & Fibre failure \\
\hline Impact \#6 & 3.70 & 1.69 & 6.21 & 3.74 & Crack initiation in back aluminium \\
\hline Impact \#7 & 4.14 & 0.42 & 14.09 & 0.50 & Crack growth in back aluminium \\
\hline Impact \#7 & 4.14 & 1.36 & 3.75 & 3.30 & Fibre failure \\
\hline Impact \#7 & 4.14 & 3.62 & 1.29 & 0.15 & Crack growth in back aluminium \\
\hline Impact \#8 & 5.42 & 0.29 & 10.46 & 0.40 & Crack initiation in top aluminium \\
\hline Impact \#8 & 5.42 & 0.30 & 13.59 & 0.40 & Crack growth in top aluminium \\
\hline
\end{tabular}

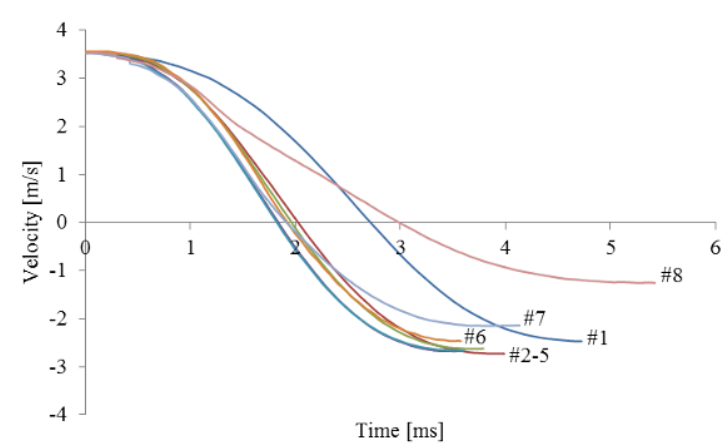

Figure 8. Velocity-time records of repeatedly impacted panels.

In Figure 5, stiffness increases with the maximum force [6]. Moreover, the sooner the maximum force, the more brittle the laminate becomes [20]. The maximum force increased by $24 \%$ from impact \#1 to \#2 and it remained constant until first cracking at impact \#6. Impact \#7 is the transition stage where the bottom crack propagated: the unloading path of the curve happened more rapidly. At impact \#8 the maximum force dropped by $40 \%$ as penetration occurred. Aluminium cracking is the ultimate failure mode in a FML under impact loading.

Zhou [20] indicated that an undamaged laminated plate presents an impact response like half a sine wave. However, damage was present in all the coupons of this investigation: ripples in Figure 5 show evidence of delamination [20]. It was present in all the impact tests except for \#1 in which it barely started. Undeniably, the sooner the peak force, the larger the damage extent is. In curve \#8, the penetration of the plate should be manifested by a final load drop at the peak of the force-time curve. In this test, the impact force was followed by a plateau at a lower level. As the conical nose was going through the plate, the contact area increased. Hence, the residual force stayed rather stable before actually reaching zero force.

The influence of glass/epoxy composite and aluminium alloy on the displacement-time curve can be depicted in Figure 9 . The maximum displacement occurred $1 \mathrm{~ms}$ sooner for the

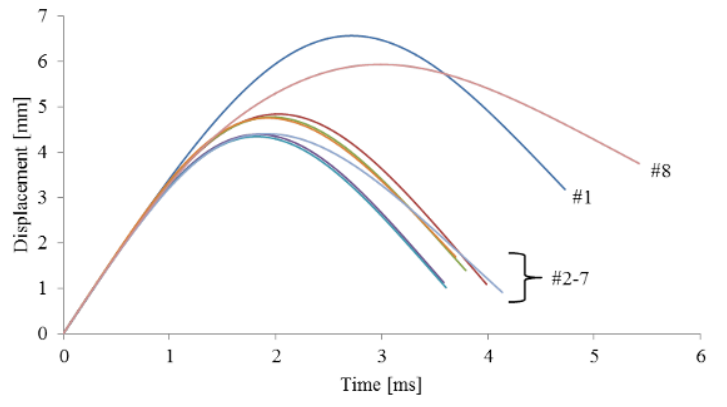

Figure 9. Recorded displacement-time curves.

plots \#2-7 than for \#1 and \#8. The analogous shape of \#2-7 indicates that the glass/epoxy plies are dominating the flexural behaviour at these impact stages while \#1 and \#8 with larger permanent flexure demonstrate that plastic deformation occurred in the aluminium layers. In comparison with Figure 5, the higher the stiffness, the sooner the maximum displacement becomes.

When relating Figure 5 to Figure 10, the resistive stiffness of the plate increased until impact \#5 because the contact time became shorter. When approaching penetration from impact \#6 onwards, contact time increased: the residual stiffness of the plate was drastically reduced. Three cases are highlighted $[20,21]$. If time at maximum force equals half of contact duration, the impact is purely elastic. If time at maximum force is shorter than half of contact duration, the larger the damage area becomes as illustrated in Figure 3. A time at maximum force longer than half of contact duration implies aluminium yielding. A dent was visible at impact \#1 on the top surface of the plate.

\subsection{Damage scenario}

Damage is detected from the first impact. A dent, plasticity of matrix, matrix cracking and delamination were observed. The impact energy was beyond the onset limit for the plasticity of matrix. The visible dent and the permanent flexural deformation bring the evidence that aluminium 


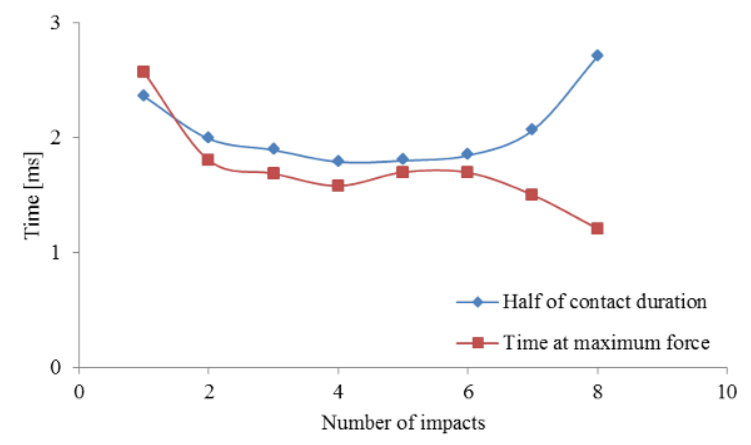

Figure 10. Half of contact duration and time at maximum force vs. the number of repeated impacts.

layers were strain-hardened. Assuming that the entire plate participated in the impact response, the strain rate amounted to $71 \mathrm{~s}^{-1}$. This experimental survey presents therefore a critical response of GLARE 5-2/1-0.3 at low velocity given that the applied strain rate was relatively high.

Based on the described phenomena the following damage sequence can be derived. When impacting a rectangular plate of GLARE 5-2/1-0.3 at low velocity, plasticity of matrix and matrix cracking occur first. Delamination within the composite plies is followed by plastic deformation of the aluminium layers. The global membrane extensional flexure of the plate induces fibre fracture. Disbonding happens at the interface between the non-impacted aluminium and the composite layer farthest from the impacted side. This local degradation reduces the plate stiffness. Hence, the indenter can further penetrate the laminate so that the dent depth and the contact area enlarge. Under larger deflection the bottom aluminium layer cannot withstand alone the highest stresses resulting from the impact force. As a result, a crack initiates and develops along the rolling direction because the aluminium cannot deform in the transverse direction as much as in the longitudinal one. Cracks appear perpendicularly to this crack, which facilitates the penetration of the projectile into the laminate. All cracks propagate and the local stiffness drops significantly: penetration occurs finally and aluminium layers undergo petaling.

When cracks in aluminium propagated, plasticity of matrix, matrix cracking, delamination, disbonding, and fibre fracture developed concurrently. These different failure modes were contained in a surface that covered approximately $250 \mathrm{~mm}^{2}$ - only $2.6 \%$ of the plate opening area whereas the permanent plate flexure amounted to about 6.6 times the plate thickness. For this reason, global plate deformation dissipates the large majority of the impact energy compared to the various failure modes that occur in FMLs. Hence, predicting the deflection profile of FMLs under impact loading would help to estimate the energy absorbed by the plate deformation. A quasi-static study can be undertaken to assess the energy balance among plate deformation and failure modes as a first approach.

\subsection{Delamination and bondline quality}

The quality of bondline and manufacturing will directly affect delamination formation and thus the impact resistance of FMLs. Abrate [22] admits that delamination shapes are often quite irregular and their orientation is somewhat difficult to ascertain. However, experimental studies report consistently that delaminations occur only at interfaces between plies with different fibre orientations. For thin laminates, the bending stresses in the back side of the laminate introduce matrix cracks and delaminations in the farthest layer from the impacted side. A reversed pine tree pattern develops through the plate thickness from these failure modes. Though the hereby tested coupons followed this trend, the observed delamination patterns evolved along the transverse direction at the impacted side and along the rolling direction at the non-impacted side. This shape has not been reported in the literature before. The delamination pattern reported in this paper may be induced either by the rectangular shape of the specimens or the indenter diameter. Caprino [9] performed impact tests in which a hemispherical impactor $15 \mathrm{~mm}$ in diameter hit square fibre-glass aluminium of $100 \mathrm{~mm}$ by $100 \mathrm{~mm}$. The delamination shape was comparable on both the impacted and the non-impacted sides. Additionally, these samples were cured at 0.7 bar whereas the pressure amounted to 6 bar in this study. The high-pressure facilitates the removal of the voids present in the laminate to deliver high-performance aerospace applications [1]. Indeed, at low-velocity impact damage mechanisms start early in a FML manufactured at low pressure [9].

Alemi Ardakani [23] observed that at low velocity the damage size is greater in laminates with low strength adhesive resins when compared to those with high strength adhesives. FMLs with good interfacial bondline present higher resistance under low-velocity impact. Contact force can be $25 \%$ higher than for samples with low-quality adhesion. Besides, FMLs with good bonding are stiffer than FMLs with poor bonding: maximum displacement can be $30 \%$ lower for FMLs with good bonding. Thus, a tight bonding is recommended at low velocity. Due to strain rate sensitivity at high velocity, it would be wise to have a low adhesion so that the layers would act as a number of separate layers. The impact resistance of a FML is directly related to the quality of the bondline and the impact regime. 


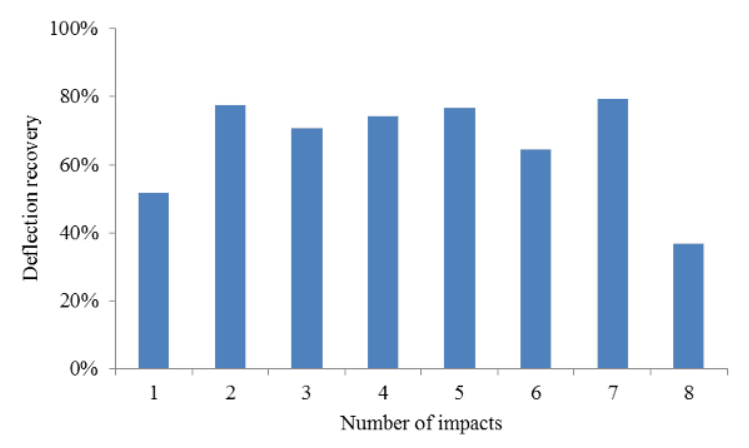

Figure 11. Deflection recovery vs. number of impacts.

\subsection{Stiffness variation}

Given that GLARE is made of glass/epoxy prepreg and aluminium alloy, several mechanisms explain why the force increases before perforation. At first, the contact area expands throughout the impact process [24]. Secondly, the strain-hardening of aluminium contributes to increasing the plate stiffness. Finally, as mentioned in Subsection 4.2 , testing was performed at low velocity but at a relatively high strain rate. At ballistic impact Armenakas [25] estimated that a strain rate of $100 \mathrm{~s}^{-1}$ can result in a $10 \%$ increase in the stiffness of unidirectional glass/epoxy. Though this effect has not been defined clearly in literature at low-velocity impact, it justifies potentially the increase in force until first cracking of the FML plate.

Deflection recovery at each number of impact is illustrated in Figure 11. The deflection recovery in steps \#2-7 ranges between $65 \%$ and $79 \%$. It means that the plate returned to $65-79 \%$ near the initial position prior to impact. The high level of recovery elucidates the excellent impact performance of FMLs over composites and monolithic aluminium alloys. In contrast with the quasi-elastic recovery of composite layers, the recovery amounts to $52 \%$ only at impact \#1. Plasticity of aluminium and matrix prevented then the glass fibres to fully spring back to their initial position. Furthermore, when penetration occurred, the deflection recovery amounted to just $37 \%$ at impact \#8: all fibres were fractured at the impact location. The glass fibres contribute effectively to delay the perforation of the plate and maintain little permanent deflection.

From this observation the idealised plate behaviour under repeated impacts can be reconstructed. Figure 12 depicts the force-displacement relations until penetration with the permanent displacement off-set of the previous test starting from record \#2.

With a repetitive quasi-elastic behaviour - slope of loading path is similar to the unloading one but at larger displacement - GLARE 5-2/1-0.3 could recover from 5 impacts of

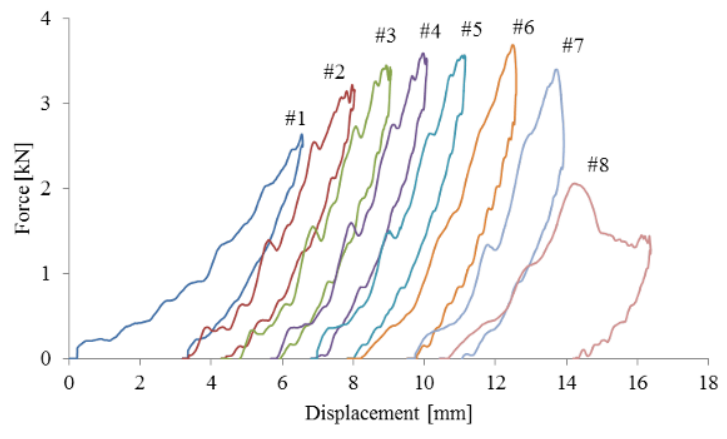

Figure 12. Force-displacement curves with displacement off-set applied from impact \#2.

a large mass before first cracking at impact \#6. Two more impacts were necessary to reach the penetration threshold. The outstanding damage tolerance capability of GLARE is the result of the high level of elastic recovery after successive impacts.

\section{Conclusion}

Damage evolution in GLARE 5-2/1-0.3 was assessed by means of repeated low-velocity impact tests. The analysis of the records was supported by visual inspection, C-scan and chemical etching. From the observations of this experimental study, the damage history was reconstructed. Its progression is briefly summarised as follows:

- plasticity and cracking of matrix with delamination and yielding of aluminium;

- disbonding at the interface between composite and aluminium;

- fracture of composite layers followed by aluminium cracking;

- penetration of the laminate and petaling of aluminium.

The interaction of the aforementioned failure modes may be complex but the global flexural deformation of the laminate absorbs most of the impact energy in FMLs. Despite a metal volume fraction of $54 \%$ in GLARE 5-2/1-0.3, aluminium cracking and petaling are effective energy absorbing failure modes compared to the low-absorbing delamination and fibre failure. However, the excellent impact resistance of GLARE results from the glass/epoxy layers that delay aluminium perforation, and from the aluminium that prevents delamination growth and penetration of the projectile. 
The repeated low-velocity impact tests provide consequently guidance for conducting modelling studies. Future work will focus on the development of a complete quasistatic analytical approach based on the energy balance.

\section{References}

[1] Vlot A., Gunnink J.W., Fibre Metal Laminates - An Introduction, Kluywer Academic Publisher, 2001.

[2] Alderliesten R.C., Homan J.J., Fatigue and damage tolerance issues of Glare in aircraft structures, Int. J. Fatig., 2006, 28(10), p. 1116-1123.

[3] Vlot A., Krull M., Impact Damage Resistance of Various Fibre Metal Laminates, J. Phys. IV France, 1997, 07(C3), p. C3-1045-C3-1050.

[4] Liaw B.M., Liu Y.X., Villars E.A., Impact Damage Mechanisms in Fiber-Metal Laminates, Proceedings of the SEM Annual Conference on Experimental and Applied Mechanics, Portland, Oregon, June 4-6, 2001.

[5] Wu G., Yang J.-M., Hahn H., The impact properties and damage tolerance and of bi-directionally reinforced fiber metal laminates, J. Mater. Sci., 2007, 42(3), p. 948-957.

[6] Seyed Yaghoubi A., Liu Y., Liaw B., Low Velocity Impact on GLARE 5 Fiber-Metal Laminates: Influences of Specimen Thickness and Impactor Mass, J. Aero. Eng., 2011.

[7] Liu Y., Liaw B., Effects of Constituents and Lay-up Configuration on Drop-Weight Tests of Fiber-Metal Laminates, Appl. Compos. Mater., 2010, 17(1): p. 4362.

[8] Sevkat E., Liaw b., Delalea F., et al., Effect of repeated impacts on the response of plain-woven hybrid composites, Composites Part B: Engineering, 2010, 41(5), p. 403-413.

[9] Caprino G., Spataro G., Del Luongo S., Low-velocity impact behaviour of fibreglass-aluminium laminates, Composites Part A: Applied Science and Manufacturing, 2004, 35(5), p. 605-616.

[10] Laliberté J., Poon C., Straznicky P.V., Low-Velocity Impact Damage in GLARE Fibre-Metal Laminates, Proceedings of International Committee on Composite Materials ICCM-12, 1999.

[11] David-West O.S., Nash D.H., and Banks W.M., An experimental study of damage accumulation in balanced CFRP laminates due to repeated impact, Compos. Struct., 2008, 83(3), p. 247-258.

[12] Belingardi G., Cavatorta M.P., Paolino D.S., On the rate of growth and extent of the steady damage accumulation phase in repeated impact tests, Compos. Sci. Tech., 2009, 69(11-12), p. 1693-1698.
[13] Rajkumar G.R., Krishna M., Narasimha Murthy H.N., et al., Effect of low velocity repeated impacts on property degradation of aluminum/glass fiber laminates, Int. J. Eng. Sci. Tech. (IJEST), 2011, 3(5), p. 4131-4140.

[14] Rajkumar G.R., Krishna M., Narasimha Murthy H.N., et al., Experimental Investigation of Low-Velocity Repeated Impacts on Glass Fiber Metal Composites, J. Mater. Eng. Perform., 2011, p. 1-6.

[15] Rajkumar G.R., Krishna M., Narasimha Murthy H.N., et al., Investigation of Repeated Low Velocity Impact Behaviour of GFRP/Aluminium and CFRP/Aluminium Laminates, Int. J. Soft Comput. Eng., 2012, 1(6), p. 5058.

[16] Fasanella E.L., Digital filtering and acceleration pulse interpretation, Full-scale transport controlled impact demontration NASA CP 2395, 1985, p. 103-123.

[17] Vlot A., Low-velocity impact loading on fibre reinforced aluminium laminates (ARALL and GLARE) and other aircraft sheet materials, Delft University of Technology, Faculty of Aerospace Engineering, Report LR-718, 1993, p. 82-136

[18] Hebsur M., Noebe R., Revilock D., Impact resistance of lightweight hybrid structures for gas turbine engine fan containment applications, J. Mater. Eng. Perform., 2003, 12(4), p. 470-479.

[19] Berthelot J.M., Matériaux composites - Comportement mécanique et analyse des structures, $4 \mathrm{e}$ édition, TEC\&DOC, 2005.

[20] Zhou G., Greaves L.J., Damage resistance and tolerance of thick laminated woven roving GFRP plates subjected to low-velocity impact, In: SR Reid, G Zhou (Eds.), Impact behaviour of fibre-reinforced composite materials and structures. Cambridge: Woodhead Publishers Ltd., 2000, p. 133-185.

[21] Liu Y., Liaw B., Drop-weight impact tests and finite element modeling of cast acrylic/aluminum plates, Polymer Test., 2009, 28(8), p. 808-823.

[22] Abrate S., Impact on composite structures, Cambridge University Press, 1998.

[23] Alemi Ardakani M., Afaghi Khatibi A., Asadollah Ghazavi S., A study on the manufacturing of Glass-FiberReinforced Aluminum Laminates and the effect of interfacial adhesive bonding on the impact behavior, Proceedings of the SEM XIth International Congress and Exposition, June 2-5, 2008, Orlando, Florida USA

[24] Jones N., Paik J.K., Impact perforation of aluminium alloy plates, International Journal of Impact Engineering, 2011, (in press), DOI: 10.1016/j.ijimpeng.2011.05.007.

[25] Armenakas A., Sciammarella C., Response of glassfiber-reinforced epoxy specimens to high rates of tensile loading, Exp. Mech., 1973, 13(10), p. 433-440. 